\title{
Terceirização na Administração Pública: Análise da Motivação dos Colaboradores Terceirizados no Serviço Público
}

\author{
Priscilla Barbosa de Oliveira Santana ${ }^{1}$; Diana Carneiro Ribeiro de Andrade ${ }^{2}$; Jorge Alberto Santana de Jesus ${ }^{3}$
}

Resumo: O presente artigo teve como finalidade realizar uma análise da motivação dos colaboradores terceirizados que fazem parte do quadro de funcionários de um hospital da rede pública do município de Petrolina-PE. Para análise do tema o método de pesquisa utilizado foram as pesquisas bibliográfica, descritiva e de campo. O referencial teórico faz um passeio pelas teorias das necessidades de Abraham Maslow, a teoria dos dois fatores de Frederick Herzberg e procura, de forma simples, contextualizar a terceirização na administração Pública. Foi realizada pesquisa in loco com aplicação de questionários, sendo os fatores analisados: remuneração, relacionamento com chefia, reconhecimento profissional, ambiente de trabalho e tratamento igualitário entre terceirizados e servidores concursados. De acordo com a análise dos dados, observa-se que, embora a maioria dos terceirizados estejam satisfeitos com o salário e ambiente, ficou caracterizada uma percepção de tratamento diferenciado, e este pode ser um fator de grande desmotivação.

Palavras-Chave: Motivação. Terceirização na Administração Pública

\section{Outsourcing in Public Administration: The Outsourced Employees Motivation Analysis in Public Service}

\begin{abstract}
This paper was to carry out an analysis of the motivation of outsourced employees who are part of the staff of a public hospital of Petrolina municipality. For theme analysis the research method used was the bibliographical research, descriptive and field. The theoretical framework makes a tour of the theories of Abraham Maslow's needs, the theory of two factors of Frederick Herzberg and demand, simply, contextualize outsourcing in public administration. Research was carried out on site with the use of questionnaires, and the factors analyzed: remuneration, relationship management, professional recognition, work environment and equal treatment between contractors and public employees. According to the data analysis, it is observed that while most contractors are satisfied with the salary and the environment, a sense of differential treatment was characterized, and this may be a factor of great motivation.
\end{abstract}

Keywords: Motivation. Outsourcing in Public Administration.

\section{Introdução}

A motivação é um tema de grande relevância na atualidade. Manter os funcionários motivados tem sido o grande desafio das organizações, com a instituição hospitalar não poderia ser diferente. $\mathrm{O}$ trabalho no ambiente hospitalar caracteriza-se por provocar um alto nível de desgaste emocional, desta forma, é indispensável que os profissionais que atuam neste ambiente, estejam preparados não só tecnicamente, mas, sobretudo, emocionalmente. Funcionários motivados tendem a desempenhar suas atividades com integridade e obtêm melhores resultados para a organização.

\footnotetext{
${ }^{1}$ Pós-graduanda em Gestão Pública pela Universidade Federal do Vale do São Francisco-UNIVASF

${ }^{2}$ Pós-graduanda em Gestão Pública pela Universidade Federal do Vale do São Francisco-UNIVASF

${ }^{3}$ Msc em Políticas Públicas pela Universidade Federal do Recôncavo da Bahia.

Contato do autor correspondente - Jorge.jesus@ univasf.edu.br
} 
Com toda a repercussão acerca da temática terceirização, muito se tem falado sobre motivação de funcionários terceirizados, diversos autores utilizaram o tema para discorrer sobre suas vantagens e desvantagens. Este artigo se propôs a analisar a motivação de servidores terceirizados no âmbito da Administração Pública Federal, utilizando o ambiente hospitalar como base para o estudo. As instituições hospitalares são empresas com um grau de complexidade maior, uma decisão equivocada pode ter uma consequência muito grave. Portanto, exige planejamento, administração eficiente de recursos humanos e financeiros, e a terceirização surge como uma proposta de gestão eficiente e redução de custos.

Guilherme Mastrichi Basso se posiciona da seguinte forma:

O tema terceirização já foi analisado e decantado em prosa e verso em todas as revistas jurídicas do país e vem sendo estudado até mesmo por outros ramos da ciência preocupados com o aumento da produtividade, a diminuição de custos, a otimização de recursos humanos e materiais, a migração da mão-de-obra, as novas tecnologias, aí incluídas a engenharia e a sociologia, dentre outros. (BASSO, 2008, p. 89)

Apesar de a terceirização apresentar vantagens para a administração pública, é preciso observar alguns fatores que podem impactar na motivação destes funcionários, como por exemplo, a discriminação, que muitas vezes é invisível, mas é algo comum para o trabalhador terceirizado. Sabemos que não só o salário é menor, mas podemos elencar outros fatores como: a distinção no tratamento, o uso do uniforme diferente, carga horária de trabalho e etc., estes pontos podem gerar um sentimento de diferença dos demais servidores, provocando insatisfação e por consequência, desmotivação.

Buscando compreender todos estes aspectos, este trabalho pretende: a) avaliar o nível de satisfação referente à remuneração, relacionamento, reconhecimento e tratamento igualitário; b) Estudar as principais teorias motivacionais; c) Contextualizar a terceirização na administração pública.

Este artigo está estruturado em cinco tópicos. No primeiro serão apresentados conceitos de motivação e suas principais teorias motivacionais. O segundo contextualiza a Terceirização na Administração Pública. O terceiro expítmle apresenta a metodologia utilizada para obtenção dos resultados. E finalmente um quarto tópico discute os números alcançados. Ao final serão apresentadas as conclusões.

\section{Motivação e suas principais Teorias}

Com base em literaturas consultadas, podemos entender que motivação é a força que impulsiona o ser humano a produzir determinado comportamento, seja ele de produtividade ou 
Id on Line Revista Multidisciplinar e de Psicoloqia

Id on Line Revista Multidisciplinar e de Psicologia

improdutividade, a favor ou contra os interesses da organização. Uma pessoa motivada, normalmente, demonstra grande disposição e satisfação na realização de suas atividades.

Mullins (2005) conceitua motivação como alguma força direcionada dentro dos indivíduos, pela qual eles tentam alcançar uma meta, a fim de preencher uma necessidade ou expectativa. Para Robbins (2005), a motivação está associada a um processo responsável pela intensidade, pela direção e pela persistência dos esforços de uma pessoa orientados para o alcance de determinado propósito. Mitchell (1982) define que a motivação pode ser intrínseca ou extrínseca. A motivação intrínseca refere-se às recompensas psicológicas, como o reconhecimento positivo do seu trabalho, ser tratado com respeito e distinção. A motivação extrínseca está relacionada a recompensas tangíveis, como satisfação com o salário recebido, benefícios, ambiente e condições de trabalho.

Através de algumas teorias que serão apresentadas abaixo, buscaremos entender melhor sobre motivação e quais os fatores que podem influenciar no comportamento humano.

\section{Teoria da Hierarquia das Necessidades - Abraham Maslow}

A teoria da Hierarquia das Necessidades apresentada por Abraham Maslow (1908-1970) é uma das principais teorias do comportamento humano. O comportamento humano é extremamente complexo e a motivação é um fator determinante. O que motiva as pessoas é a satisfação de suas necessidades e, segundo Maslow, estas necessidades podem ser hierarquizadas.

Robbins (2002) expõe com simplicidade o funcionamento da teoria de Maslow: "existe uma hierarquia de cinco necessidades [...] e, à medida que cada uma delas é satisfeita, a seguinte torna-se dominante".

Maslow desenvolveu a tese de que as necessidades humanas podem ser divididas em cinco grupos, conforme podemos ver abaixo na figura 1:

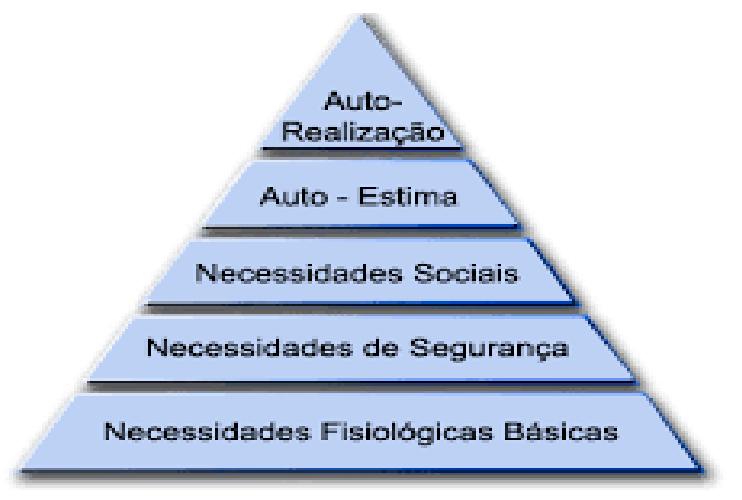

Figura 1: Pirâmide das necessidades humanas Fonte: Maslow 2003. 
Id on Line Revista Multidisciplinar e de Psicologia

Id on Line Revista Multidisciplinar e de Psicologia

- As necessidades fisiológicas ou básicas refere-se a sobrevivência humana, como a alimentação, habitação, vestuários etc. Essas necessidades são as mais importantes e de maior impacto, desta forma, suprir estas necessidades primeiro, ainda que incosciente, torna-se prioridade. Megginson, Mosley e Pietri Jr (1986) afirmam que nada tem tanta importância na vida do ser humano se este não tiver do que se alimentar. Mas, logo que saciar a sua fome, a pessoa, então, passa a sentir outras necessidades.

- As necessidades de segurança dizem respeito a proteção contra ameaças, como a ameaça a integridade física e à sobrevivência, a perda de emprego, proteção contra doeças etc. Normalmente, a partir do momento em que as necessidades básicas são supridas, é dada maior atenção as necessidades de segurança. Chiavenato (2004) coloca que as necessidades deste nível têm relação com a estabilidade na vida das pessoas: ter "segurança, proteção contra ameaça ou perigo físico e emocional".

- As necessidades sociais concerne na ideia de aceitação, de pertencer a determinado grupo social, necessidade de amizade, afeto etc. Ainda sobre a importância de que esta necessidade seja satisfeita, Silva (2008) comenta que a frustração das necessidades de afeto e amor, conduz à solidão e à inadaptação social. Essas necessidades quando satisfeitas, são importantes forças motivadoras.

- As necessidades de Estima remete-se a imagem que o indivíduo tem de si, a forma como se avalia. Corresponde a autoconfiança, aprovação social, sensação de capacidade, valor, poder, utilidade etc. Segundo Megginson, Mosley e Pietri Jr (1986) as necessidades de estima dificilmente serão satisfeitas por completo, visto que estes tipos de necessidades são constatemente procuradas pelas pessoas que vêem o seu trabalho como algo muito importante.

- Necessidades de autorrealiação, esta fica no topo da pirâmide por que são as necessidades mais elevadas. Refere-se a realização interior, a busca por ser melhor e de mostrar que tem potencial para desenvolver algo grande e admirável.

A teoria das necessidades de Abraham Maslow é considerada uma das mais importantes explicações sobre a motivação. De acordo com o autor, quanto maior a necessidade de uma pessoa, mais forte será sua motivação, mas, assim que tal necessidade é satisfeita, extingue-se também a força que impulsiona e movimenta o comportamento humano, terminando assim a sua motivação.

\section{Teoria dos Dois Fatores - Frederick Herzberg}

A Teoria dos Dois Fatores de Frederick Herzberg (1923-2000) pode ser considerada, segundo Silva (2008, p. 213) "uma extensão interessante da teoria da Hierarquia das Necessidades de Maslow". 
Id on Line Revista Multidisciplinar e de Psicologia

Id on Line Revista Multidisciplinar e de Psicologia

Frederick Herzberg foi o estudioso que mais enfatizou a importância da motivação no trabalho, de acordo com Marras (2000).

Sua teoria surgiu da análise de 'incidentes críticos', que foram extraídos de entrevistas com pessoas em diversas empresas e países, com o intuito de responder o que provocava satisfação ou insatisfação no trabalho. A partir da análise dos resultados, Herzberg percebeu que a satisfação e insatisfação das pessoas podiam ser divididas em dois fatores: Fatores extrínsecos - que são fatores associados com as condições sob as quais o trabalho é realizado. E Fatores intrínsecos - Estes estão relacionados com a motivação que o trabalho pode causar ao indivíduo. Desta forma, Herzberg os denominou de Fatores de higiene e Fatores de motivação, respectivamente.

Observando a figura 2, é possível termos noção do que Herzberg caracteriza de fatores de higiene e motivação.

Figura 2: Quadro de Fatores de higiene e motivação

\begin{tabular}{|c|c|}
\hline Fatores de higiene ou extrínseco & Fatores de motivação ou intrínseco \\
\hline $\begin{array}{l}\text { *Estilo de supervisão do chefe. } \\
\text { *Relações pessoais com os colegas de } \\
\text { trabalho. } \\
\text { * Salário. } \\
\text { *Políticas de administração de pessoal. } \\
\text { *Condições físicas e segurança do trabalho. }\end{array}$ & $\begin{array}{l}\text { *Conteúdo de trabalho em si } \\
\text { *Sentido de realização de algo importante. } \\
\text { *Exercício da responsabilidade. } \\
\text { *Possibilidade de crescimento. } \\
\text { *Orgulho e sentimento de prestígio } \\
\text { decorrentes da profissão. } \\
\text { *Reconhecimento pelo trabalho bem feito. }\end{array}$ \\
\hline
\end{tabular}

Fonte: Maximiano, Antonio Cesar Amaru (2006)

Ainda sobre os fatores higiênicos, podemos concluir que estes são responsáveis por tornar o ambiente mais saudável. O bom relacionamento com os colegas e com a chefia tornam os funcionários mais satisfeitos com seu trabalho. Da mesma forma se estiverem satisfeitos com o salário recebido. Maximiano (2006, p. 268) "Quanto mais contente a pessoa estiver com o salário, menor será sua disposição para reclamar deste aspecto de sua relação com a empresa".

Quantos aos fatores motivacionais, para Herzberg (1959), é preciso que a pessoa esteja sintonizada com seu trabalho, que enxergue nele a possibilidade de exercitar suas habilidades ou desenvolver suas aptidões. De acordo com Silva (2008, p. 214), "Os fatores de motivação estão associados a sentimentos positivos dos empregados sobre seu trabalho".

Para Herzberg, satisfação e insatisfação são dimensões independentes. A satisfação não é obrigatoriamente o sentido oposto de insatisfação. O indivíduo pode não está satisfeito com o seu trabalho, mas isso não quer dizer que ele esteja insatisfeito. Da mesma forma que se ele não estiver insatisfeito, não estará necessariamente satisfeito. Nem sempre ao eliminar a situação que cause insatisfação no trabalho, resultará em satisfação. Desta forma, Herzberg considerou que o oposto de satisfação é não satisfação e de insatisfação é não insatisfação. 
Id on Line Revista Multidisciplinar e de Psicologia

Id on Line Revista Multidisciplinar e de Psicologia

\section{Comparação entre os modelos de Maslow e Herzberg}

Para Silva (2008, p. 216) umas das principais razões da popularidade da teoria dos dois fatores de Herzberg é a compatibilidade com a teoria da hierarquia das necessidades de Maslow. Maslow e Herzberg têm teorias simples e destacam pontos parecidos acerca dos fatores que motivam o ser humano.

Podemos fazer uma relação dos fatores higiênicos de Herzberg, com as necessidades primárias da pirâmide de Maslow, como as fisiológicas, segurança e sociais. Assim como os fatores motivacionais que correspondem ao topo da pirâmide, que são as necessidades de autoestima e autorrealização.

Observemos a figura 3: Relação entre as teorias de Maslow e Herzberg.

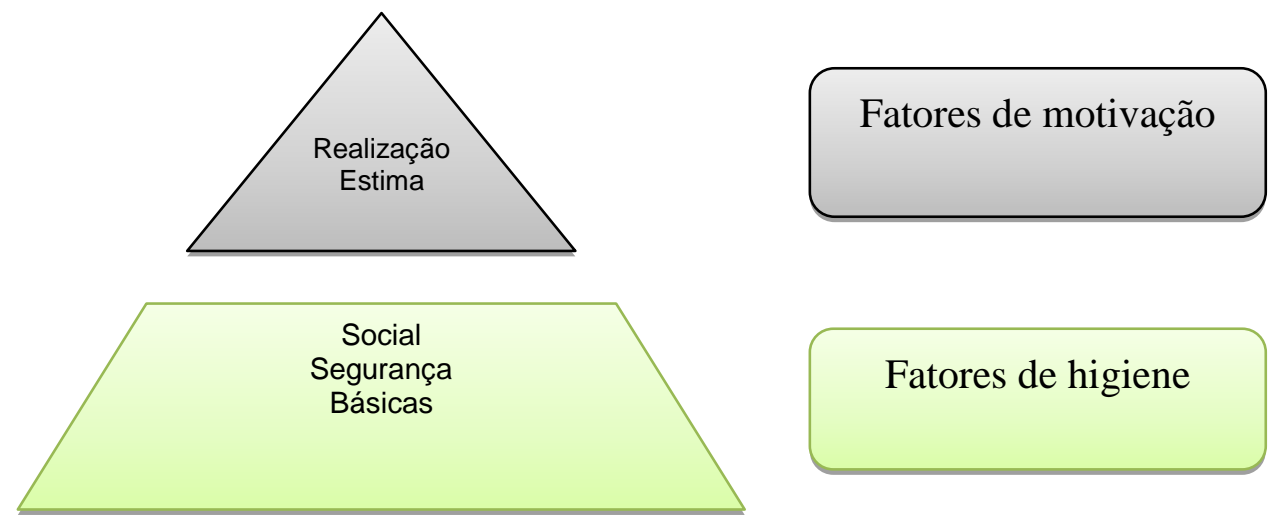

Figura 3: Comparação entre as teorias de Maslow e Herzberg Fonte: Adaptado de Silva, Reinaldo O. (2008)

Chiavenato (2003) afirma que a principal diferença entre as teorias de Maslow e a de Herzberg é em relação ao ponto de referência que serviu de base para os estudiosos: enquanto Maslow observou a motivação dentro das necessidades humanas, Herzberg a analisou considerando o ambiente externo e o trabalho do indivíduo.

Silva (2008, p. 216) "Maslow formulou sua teoria em termos de necessidade, e Herzberg, em termos de metas ou recompensas". Herzberg sugeriu que os fatores higiênicos pudessem ajudar as pessoas a sustentar os níveis mais baixos de necessidades. Já os motivadores para os níveis mais altos de necessidades. Maslow faz referencia a uma hierarquia de necessidades, sendo sua força ainda não ter sido satisfeita tal necessidade e a partir daí sua motivação para satisfazê-la. 
Id on Line Revista Multidisciplinar e de Psicoloqia

Id on Line Revista Multidisciplinar e de Psicologia

\section{Terceirização na Administração Pública}

A terceirização é uma técnica que vem sendo utilizada em larga escala e é vista como uma alternativa de desverticalização para tornar as organizações mais flexíveis às mudanças do mercado (RUSSO; LEITÃO, 2006, p. 107). Para Biavaschi (2008) A terceirização é o método de contratação que mais avançou no Brasil a partir da década de 90. Sendo atualmente uma técnica bastante utilizada em vários segmentos econômicos, das esferas pública e privada.

Para Silva e Siluk (2007, p. 2) a terceirização pode ser definida como:

A terceirização é como um processo de gestão moderno assumiu o seu papel no cenário da Administração e vem contribuindo para o fortalecimento da competitividade, onde as organizações estão terceirizando serviços que não fazem parte do foco do seu negócio.

Podemos entender por terceirização, conforme interpretação de Silva e Siluk (2007, p. 5) o processo pelo qual uma empresa, visando alcançar maior qualidade, produtividade e redução de custos, repassa a outra empresa um determinado serviço. De acordo com este entendimento, esta atividade deixa de ser desenvolvida pelos servidores concursados, no caso da administração pública, e a execução da atividade passa a ser responsabilidade da empresa contratada.

A terceirização na administração pública é regulamentada pela Lei 8.666/93 (lei de licitações e contratos da Administração Pública), que estabelece normas gerais a serem seguidas no processo de contratação de uma empresa para prestar serviço a Administração Pública.

A Instrução Normativa 02 de 30 de abril de 2008, do Ministério do Planejamento, Orçamento e Gestão (MPOG) também dispõe de regras e diretrizes para a contratação de serviços. Em seu Art $6^{\circ}$ especifica que os serviços continuados que podem ser contratados de terceiros pela Administração são aqueles que apoiam a realização das atividades essenciais ao cumprimento da missão institucional.

O Art. 14 Prevê que a contratação de prestação de serviços será sempre precedida da apresentação do Projeto Básico ou Termo de Referência [...] devendo o Projeto ou Termo de Referência ser justificado e aprovado pela autoridade competente.

O Art. 15 afirma que o Projeto ou TR precisa justificar a necessidade da contratação, benefícios diretos e indiretos [...] custo estimado da contratação e etc.

A contratação de uma empresa terceirizada é feita através processo licitatório. $\mathrm{O}$ Art. $3^{\circ}$ da lei 8.666/93 dispõe que:

A licitação destina-se a garantir a observância do princípio constitucional da isonomia, a seleção da proposta mais vantajosa para a administração e a promoção do desenvolvimento nacional sustentável e será processada e julgada em estrita conformidade com os princípios básicos da legalidade, da impessoalidade, da moralidade, da igualdade, da publicidade, da probidade administrativa, da vinculação ao instrumento convocatório, do julgamento objetivo e dos que lhes são correlatos. 
O Art. $7^{\circ}$ da Instrução Normativa 02 enfatiza que os serviços de limpeza, segurança, vigilância, transportes, informática, recepção, manutenção de equipamentos e instalações, podem ser objeto de terceirização. O Decreto-Lei no 200 de 25 de fevereiro de 1967, Art. 10, §7º diz que: "[...] com o objetivo de impedir o crescimento desmesurado da máquina administrativa, a administração procurará desobrigar-se da realização material das tarefas executivas, recorrendo, sempre que possível, à execução indireta". A partir da análise desta citação, fica clara que a ideia de terceirização já era vista como uma proposta de redução de custo para a Administração Pública há muito anos atrás.

Heringuer, Ramos e Santiago (2011) A terceirização ganha importância em um momento em que as empresas precisam racionalizar recursos, redefinir suas operações, funcionar com estruturas mais enxutas e flexíveis. Desta forma, torna-se um instrumento de auxílio à reconstrução organizacional, aumento da produtividade e competitividade.

Embora o terceirizado não faça parte do quadro de funcionários é importante que ele se sinta parte essencial do processo. (Heringuer et. al. 2011, p. 85). É comum ao trabalhador terceirizado se deparar com situações de tratamento diferente em relação aos demais trabalhadores que são servidores públicos. Miranda (2014) comenta que a diferença social e as condições de trabalho entre terceirizados e servidores públicos é notável e faz com que estes se sintam rejeitados e discriminados.

\section{Metodologia}

Para alcançarmos os objetivos propostos neste artigo, foram utilizados os métodos de pesquisas: bibliográfica, descritiva e de campo.

A pesquisa bibliográfica procura esclarecer um problema a partir de referências teóricas publicadas em documentos. Pode ter caráter descritivo ou experimental. Em todos os casos, analisa o assunto desde a sua origem.

De acordo com Ruiz (2006, p.58) temos que pesquisa bibliográfica:

Consiste no exame de bibliografia, para levantamento e análise do que já se produziu sobre o determinado assunto que assumimos e como tema de pesquisa científica. Bibliografia é o conjunto dos livros escritos sobre determinado assunto por autores identificados ou anônimos, pertencentes à correntes de pensamentos diversas entre si, ao longo da evolução da humanidade.

Assim, este trabalho desenvolveu-se a partir do exame das obras de diversos autores, a fim de buscar fundamentação teórica as considerações que ao final serão apresentadas.

A pesquisa é descritiva porque buscou descrever de forma precisa a situação motivacional dos terceirizados que fazem parte do quadro de funcionários do hospital estudado. Gil (2008) comenta a 
Id on Line Revista Multidisciplinar e de Psicoloqia

Id on Line Revista Multidisciplinar e de Psicologia

pesquisa descritiva como descrever as características de determinadas populações utilizando técnicas de coletas de dados.

Quanto à pesquisa de campo, esta foi realizada em um hospital da rede pública do município de Petrolina - PE. Foram entrevistados funcionários terceirizados com aplicação de questionários. Vergara (2009) afirma que pesquisa de campo é realizada no local onde ocorre ou ocorreu uma situação que disponibilize elementos para explica-la, que pode ser através aplicação de questionários.

\section{Amostra da Pesquisa}

O hospital estudado possui um quadro de funcionários terceirizados que prestam serviço de apoio administrativo. São 148 (cento e quarenta e oito) terceirizados atuando como secretárias, motoristas, serviço de manutenção, recepcionistas, porteiros e etc.

Para tornar o resultado da pesquisa válido, foi realizado cálculo da amostra e utilizado o nível de significância de 5\%, ou seja, a amostra tem $95 \%$ de confiança.

Barbetta (2003, p. 41) utiliza a fórmula abaixo para o cálculo da amostra:

$$
n=\frac{N * n 0}{N+n 0} \quad n 0=\frac{1}{(E 0)^{2}}
$$

$\mathrm{N}=$ corresponde ao tamanho da população;

$\mathrm{E} 0=$ erro amostral tolerável;

n0= primeira aproximação do tamanho da amostra;

$\mathrm{n}=$ tamanho da amostra.

Calculando a amostra específica:

$\mathrm{n} 0=1 /(0,05)^{2}=400$ pessoas

$\mathrm{n}=(148 \mathrm{x} 400) /(148+400)=\mathbf{1 0 8}($ cento e oito $)$ pessoas

Desta forma, após cálculo da amostra, ficou definido que 108 (cento e oito) terceirizados deveriam responder ao questionário. Foi acordado com a administração do hospital um dia para realização da pesquisa. Nesta oportunidade, foram distribuídos os questionários e realizada uma explanação do tema e objetivo do trabalho, ao final do dia, dos 110 (cento e dez) questionários disponibilizados, 102 (cento e dois) retornaram, faltando apenas 6 (seis) para completar a amostra. Diante do baixo número de evasão, entendemos que a pesquisa não foi prejudicada.

\section{Análise de Dados}


Id on Line Revista Multidisciplinar e de Psicologia

Id on Line Revista Multidisciplinar e de Psicologia

Inicialmente serão apresentados os dados relacionados ao perfil dos participantes.

- Dos 102 terceirizados respondentes, $58 \%$ são do sexo feminino e $42 \%$ do sexo masculino.

- Quanto ao grau de escolaridade: A maior parte dos respondentes que corresponde a 65\% cursou até o ensino médio. 17\% possuem ensino superior incompleto, $9 \%$ concluíram o ensino superior e $4 \%$ possuem o título de pós-graduado. $2 \%$ dos respondentes não forneceram esta informação.

- Em relação ao tempo de serviço: 53\% estão trabalhando no hospital até 1 ano, $17 \%$ de 1 a 2 anos, $12 \%$ de 2 a 4 anos e $18 \%$ mais de 4 anos.

Dando seguimento a análise das respostas dos questionários, iremos verificar as perguntas que justificam se os funcionários terceirizados sentem-se motivados.

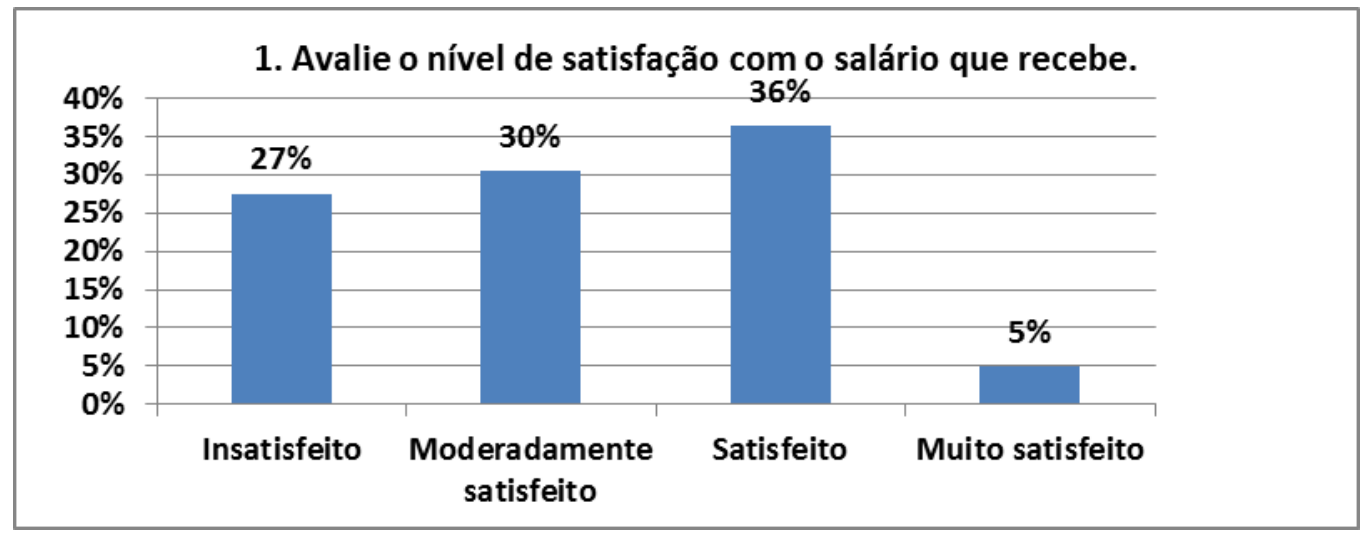

A primeira pergunta trata-se de uma avaliação do nível de satisfação com o salário recebido. Nota-se que $36 \%$ dos respondentes estão satisfeitos com salário recebido, $30 \%$ estão moderadamente satisfeitos, 5\% estão muito satisfeitos e $27 \%$ sentem-se insatisfeitos. Apesar da quantidade de terceirizados satisfeitos com o valor recebido serem maior que a quantidade de insatisfeitos, este quantitativo de $27 \%$ também é um número bastante representativo e deve ser levado em consideração. Segundo Herzberg, salário é um fator extrínseco, não causa motivação, mas previne a insatisfação. De acordo com Maximiano (2006, p. 268) "Quanto mais contente a pessoa estiver com o salário, menor será sua disposição para reclamar deste aspecto de sua relação com a empresa". 


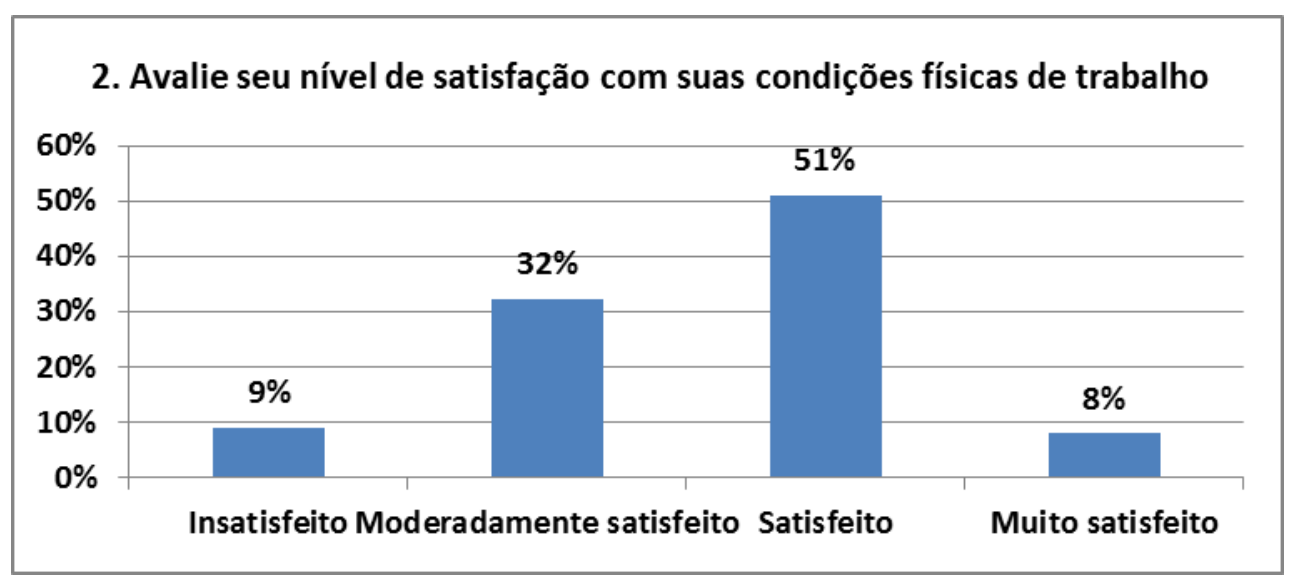

Continuando a análise, a segunda pergunta refere-se à satisfação com o ambiente físico de trabalho (ventilação, iluminação, espaço, limpeza, equipamentos, móveis e etc.), percebe-se que $51 \%$ declararam que estão satisfeitos com seu ambiente físico de trabalho. 32\% dizem está moderadamente satisfeitos, $8 \%$ muito satisfeitos e $9 \%$ informaram que estão insatisfeitos. Os fatores relacionados ao ambiente de trabalho, também são chamados de fatores extrínsecos ou de higiene, conforme Herzberg. Ainda de acordo com Silva (2008, p. 213) "Os fatores de higiene não produzem nenhum crescimento nas respostas do trabalhador, mas evitam perda no desempenho, causada por restrição de trabalho". Maximiano (2006, p. 268) "Ambiente de trabalho produz satisfação ou insatisfação com o próprio ambiente, mas não motivação com o trabalho".

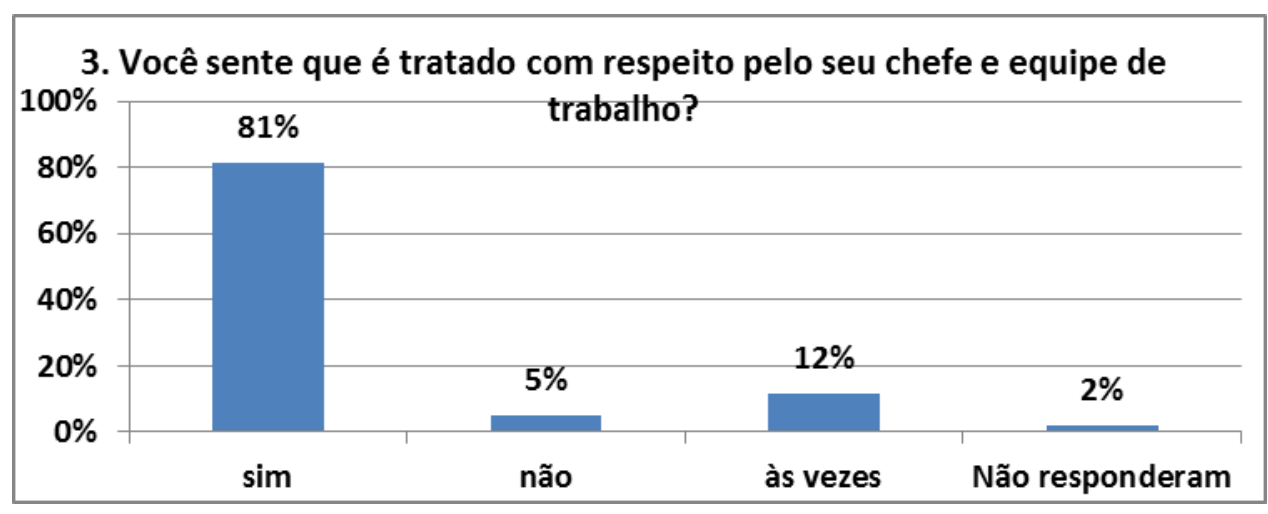

A terceira pergunta questiona se o (terceirizado sente que é tratado com respeito pelo seu chefe e equipe de trabalho). Com base no levantamento de dados, temos que $81 \%$ dos respondentes declararam sentir-se tratados com respeito pelo chefe e equipe. $12 \%$ informaram que às vezes, $5 \%$ entendem que não são tratados com respeito pela chefia e equipe de trabalho. 
Id on Line Revista Multidisciplinar e de Psicologia

Id on Line Revista Multidisciplinar e de Psicologia

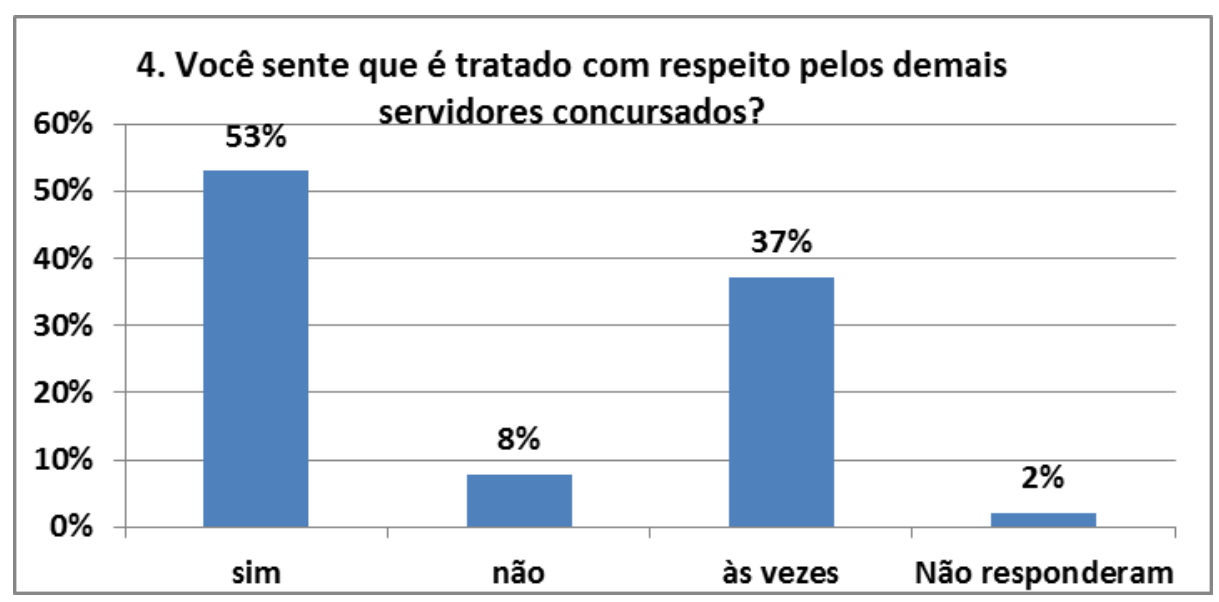

Prosseguindo com a análise, observa-se a pergunta 4 (Tratamento respeitoso pelos demais servidores concursados), percebe-se que a maioria dos respondentes, que totalizam 53\%, dizem que são tratados com respeito. $37 \%$ declararam que às vezes são tratados com respeito e às vezes não. $8 \%$ revelaram que os servidores concursados não os tratam com respeito. Ainda tendo a teoria dos dois fatores como base de análise, esta pergunta tem relação com o fator intrínseco ou de motivação. Segundo Silva (2006, p. 214) "Os fatores de motivação estão associados a sentimentos positivos dos empregados sobre o trabalho". Maximiano (2006) faz uma relação dos fatores motivacionais com o topo da pirâmide de Abraham Maslow. Quanto mais se sobe os degraus da pirâmide de Maslow, mais importante tornam-se os fatores motivacionais da teoria dos dois fatores de Herzberg.

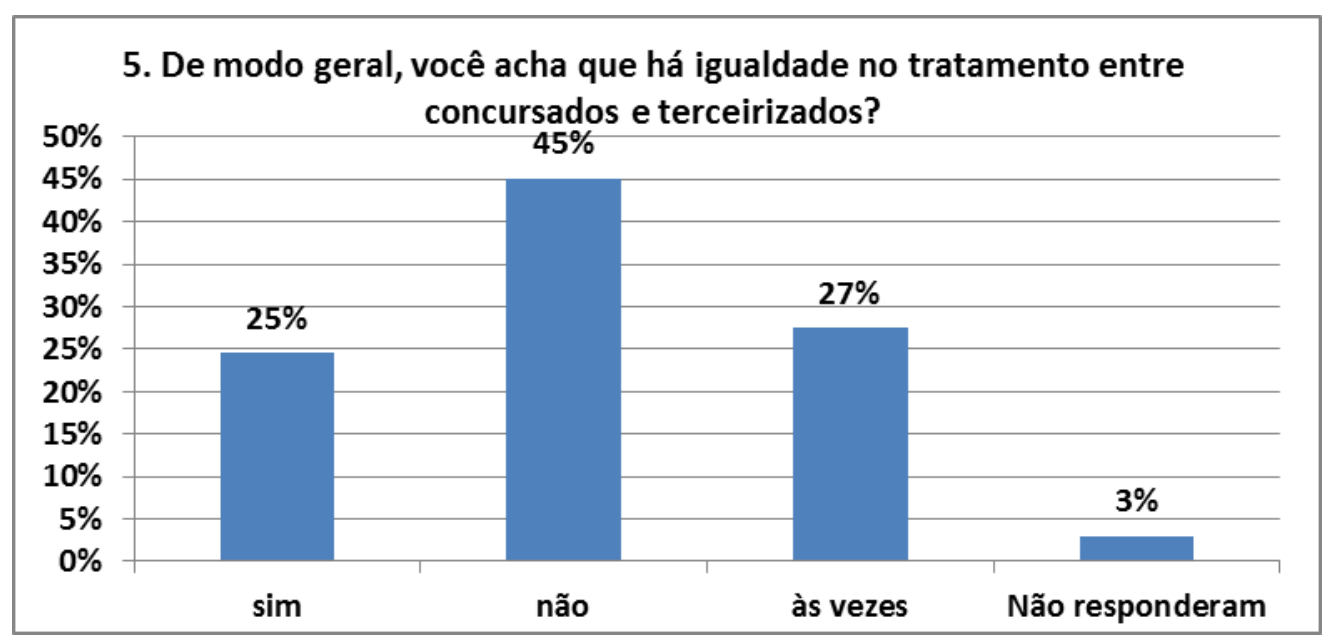

Verificando os dados da pergunta 5 (Igualdade no tratamento entre concursados e terceirizados), nota-se que $45 \%$ dizem que o tratamento é diferenciado, $27 \%$ sentem que as vezes e $25 \%$ entendem que o tratamento é igual. Este é um fator bastante importante para a saúde psicológica do trabalhador. 
Id on Line Revista Multidisciplinar e de Psicologia

Id on Line Revista Multidisciplinar e de Psicologia

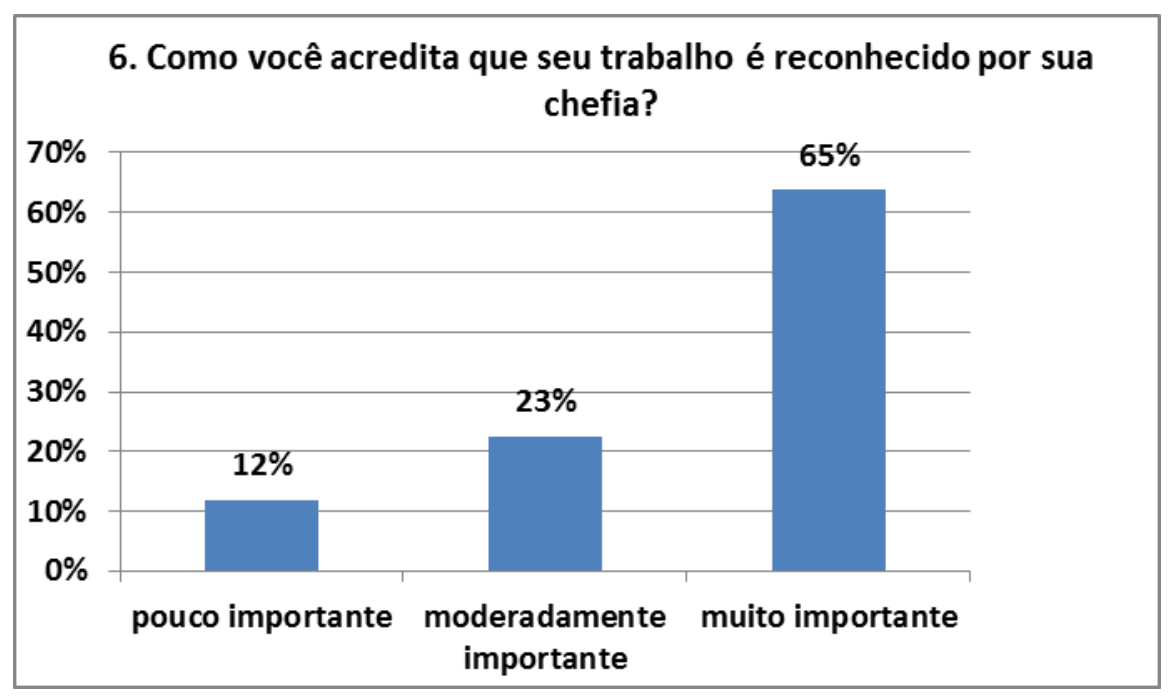

A pergunta 6, trata de reconhecimento (como o trabalho é reconhecido pela chefia), $65 \%$ disseram que seu trabalho é visto pela chefia como muito importante, $23 \%$ moderadamente importante e $12 \%$ entendem que seu trabalho não é valorizado. Observa-se que a pergunta 5 e 6 estão interligadas. Maximiano (2006) comenta que quanto melhor a relação entre colegas e o tratamento recebido pela chefia, melhor será o clima organizacional.

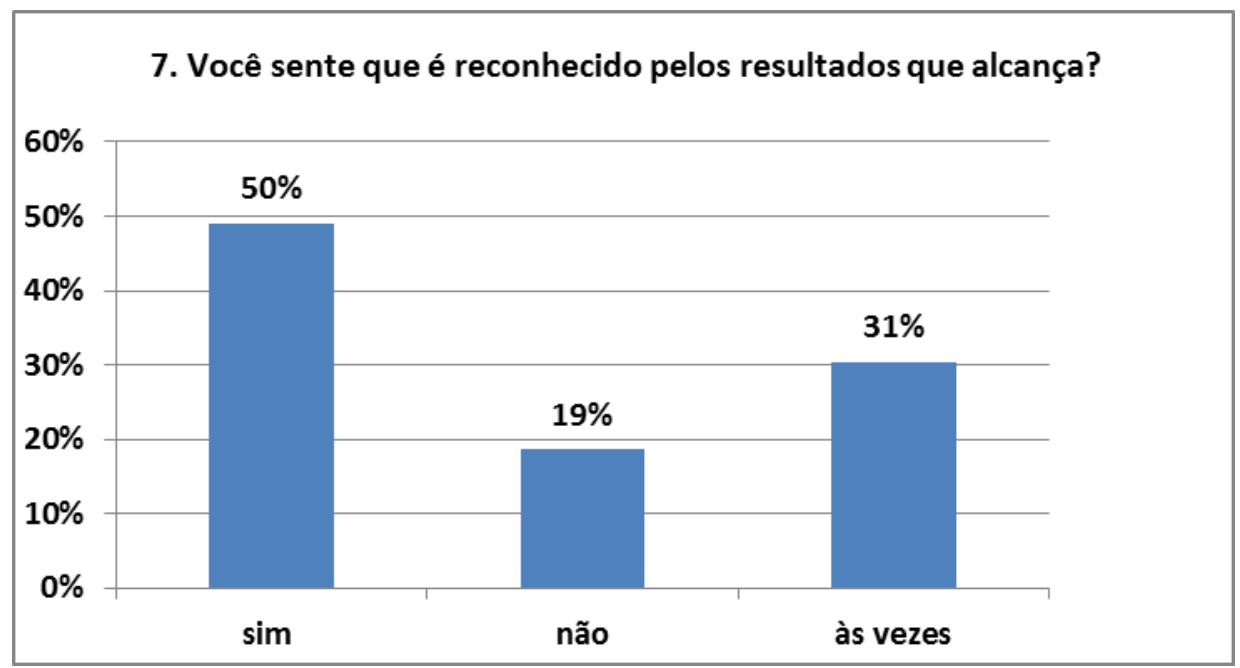

Observando o levantamento de dados da pergunta 7 (reconhecido pelo resultado que alcança), $50 \%$ afirmaram que sim, $31 \%$ entendem que as vezes existe o reconhecimento e $19 \%$ não sente seu trabalho reconhecido. O reconhecimento faz parte dos fatores motivacionais. Sentir-se valorizado pode levar o funcionário a autorrealização. 


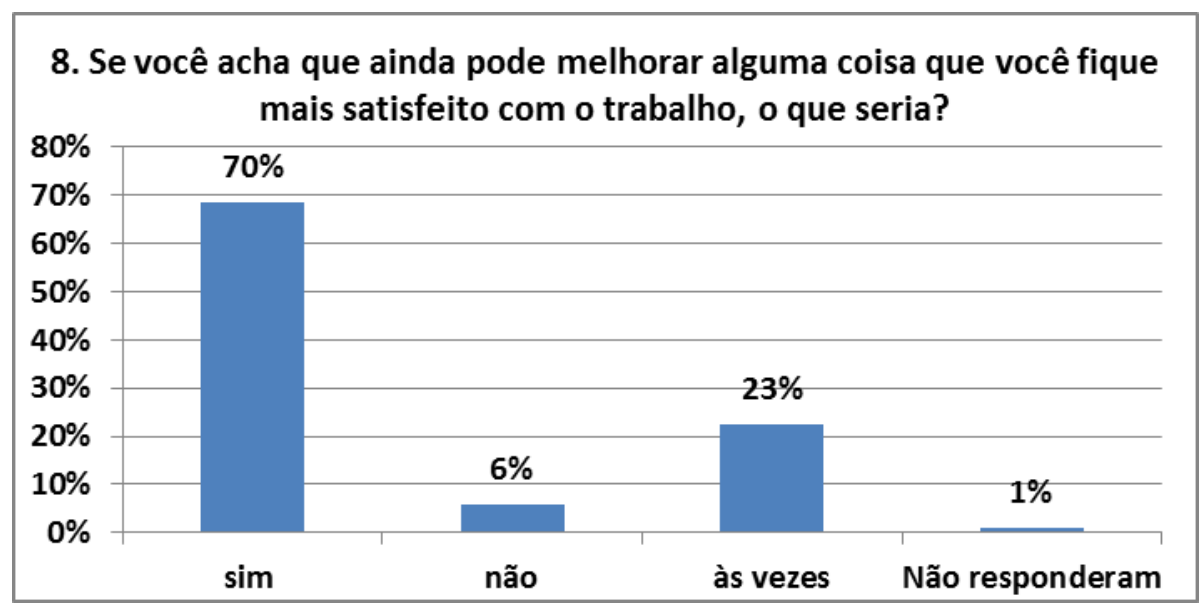

A pergunta 8 (se as pessoas cooperam para que o trabalho seja realizado), 70\% responderam que sim, $23 \%$ às vezes e $6 \%$ não contam com a colaboração da equipe para realização das atividades. A relação de cooperação e reciprocidade dentro da organização aumenta sua eficiência. O trabalho em equipe maximiza os pontos fortes dos indivíduos e minimiza suas fraquezas, tornando o ambiente produtivo.

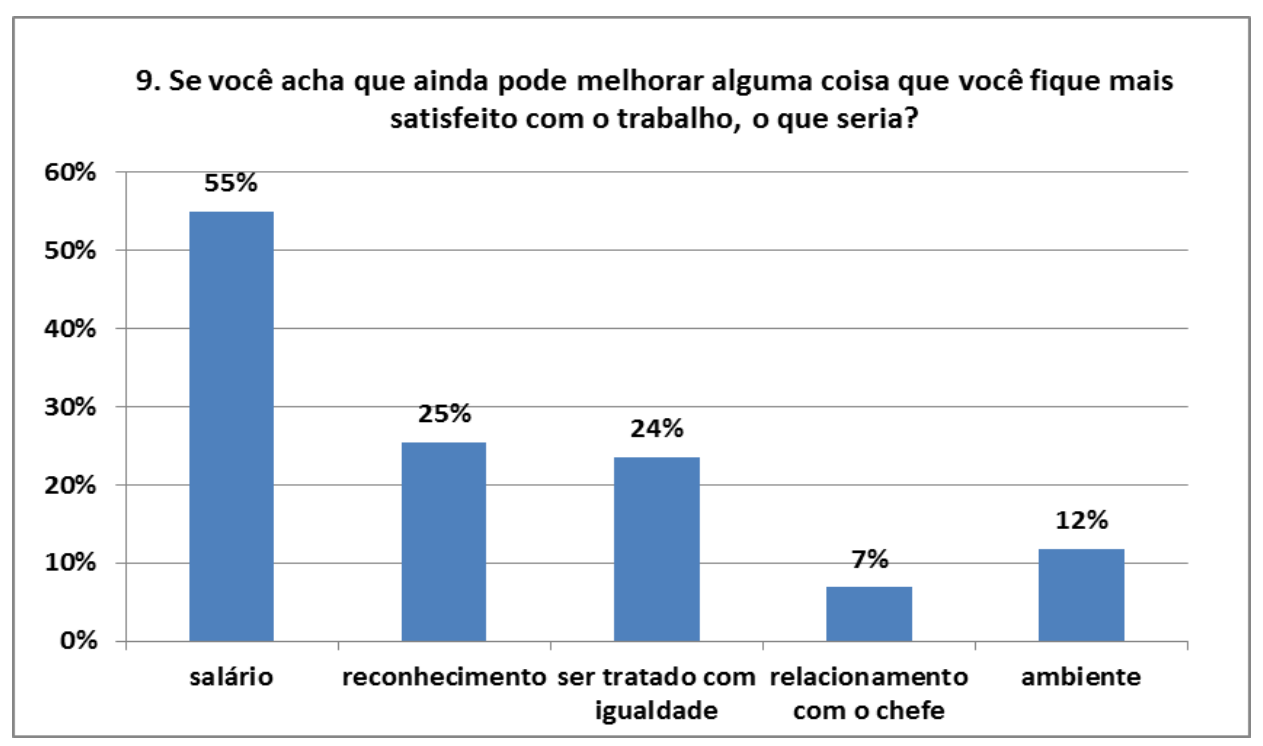

Para finalizar a exposição dos dados, a pergunta 9 questiona sobre possibilidade de melhoria (o que é preciso para melhorar a satisfação), nesta pergunta, alguns entrevistados optaram por marcar mais de uma alternativa, desta forma temos que: $56 \%$ entenderam que o salário seria um fator de maior impulso motivacional, $26 \%$ afirmam ser o reconhecimento da chefia, $24 \%$ escolheram ser tratado com igualdade, $12 \%$ entendem que o ambiente precisa melhorar e $7 \%$ o relacionamento com a chefia. 
Id on Line Revista Multidisciplinar e de Psicologia

Id on Line Revista Multidisciplinar e de Psicologia

\section{Considerações Finais}

Este artigo realizou uma análise da motivação dos colaboradores terceirizados que fazem parte do quadro de funcionários de um hospital da rede pública do município de Petrolina-PE. A Teoria da Hierarquia das Necessidades de Maslow e a Teoria dos Dois Fatores de Herzberg são eficientes em apontar elementos que produzem motivação. Cada indivíduo tem suas necessidades, desejos e expressam de maneira particular, de acordo com suas características individuais. A terceirização, além de ser uma ferramenta estratégica de gestão e redução de custo, torna-se um método eficiente, mas que requer cautela, com o propósito de evitar a desmotivação destes funcionários.

De acordo com a análise de dados, percebe-se que a maior parte dos respondentes estão satisfeitos com o salário recebido, no entanto, quando perguntado o que pode melhorar a motivação, o fator salário foi o mais escolhido. $\mathrm{O}$ que pode estar relacionado com a diferença do salário do terceirizado com o do servidor público. Relembrando as palavras de Herzberg, o salário não causa motivação, mas previne a insatisfação.

Foi possível identificar que existe satisfação quanto à estrutura do ambiente, tratamento recebido pela chefia e demais servidores, reconhecimento da chefia, resultados alcançados e cooperação da equipe. Mas quando questionados acerca da igualdade de tratamento, a maioria entende que não há igualdade. Esta opinião pode desencadear o sentimento de injustiça, que tem capacidade de desmotivá-los para o trabalho.

Diante dos resultados, sugere-se que a organização trabalhe fortemente na perspectiva de diminuir o sentimento de desigualdade evidenciado. O funcionário terceirizado, apesar de uma situação contratual diferente, parece desenvolver as suas atividades no hospital, com o mesmo objetivo do servidor público. Portanto, é fundamental para a motivação e satisfação destes, serem tratados com respeito e equidade. A Constituição Federal de $1988 \mathrm{em}$ seu art. $5^{\circ}$ é bastante claro quando garante que todos são iguais perante a lei, sem distinção de qualquer natureza. Logo, o tratamento desigual ou discriminatório motivado pela condição contratual é configura-se um desrespeito à lei.

$\mathrm{O}$ tratamento justo e humanizado, tende a gerar sentimentos e atitudes mais nobres, tais como a sensação de pertença e comportamentos solidários. Estes, pilares para uma maior motivação pessoal e laboral.

\section{Referências}

BARBETTA, Pedro Alberto. Estatística aplicada às ciências sociais. 4. ed. Local: Santa Catarina:UFSC, 2003, P.41. 
Id on Line Revista Multidisciplinar e de Psicoloqia

Id on Line Revista Multidisciplinar e de Psicologia

BASSO, Guilherme Mastrichi. Terceirização e mundo globalizado: o encadeamento produtivo e a complementaridade de serviços como potencializadores da formalização de contratos. Vol. $74, \mathrm{n}^{\circ}$ 4, Local Brasília, 2008, p. 89

BIAVASCHI, Magda Barros. A Terceirização e a Justiça do Trabalho. Vol. 74. N 4. Revista TST, Brasília, 2008.

BRASIL, Lei $\quad \mathbf{8 . 6 6 6}, \quad$ de $21 \quad$ de $\quad$ junho de 1993 . http://www.planalto.gov.br/ccivil 03/leis/L8666cons.htm acesso em junho de 2016.

Instrução Normativa N $\mathbf{0 2}$, de 30 de abril de 2008. http://www.comprasgovernamentais.gov.br/paginas/instrucoes-normativas/instrucao-normativa-no-02de-30-de-abril-de-2008-1 acesso em junho de 2016.

Decreto-Lei $\mathbf{N}^{\mathbf{2}} \quad \mathbf{2 0 0}$, de 25 de fevereiro de 1967. http://www.planalto.gov.br/ccivil_03/decreto-lei/Del0200.htm acesso em junho de 2016.

Constituição da República Federativa do Brasil de 1988. http://www.planalto.gov.br/ccivil_03/Constituicao/Constituicao.htm acesso em junho de 2016.

CHIAVENATO, Idalberto. Administração de recursos humanos: fundamentos básicos. 5. ed. São Paulo: Atlas, 2003.

. Administração nos novos tempos. 2.ed. rev. atual. Rio de Janeiro: Campus, 2004.

GIL, Antonio Carlos. Como elaborar projetos de pesquisa. 4 ed. São Paulo: Atlas, 2008.

HERINGUER, Benedita Hirene de França, RAMOS, Camila Soares da Silva e SANTIAGO, Marcia Rodrigues. A Díade vantagem e desvantagem: estudo de caso de terceirização da área de recursos humanos. V. 4, No 4, 2011.

RUSSO, Giuseppe Maria e LEITÃO, Sergio Proença. Terceirização: Uma Análise Desconstrutiva. V. 13. No. $36-2006$

LAURIE, Mullins, Management and organizational behaviour, 5 ed. Londres: Pitman, 2005.

MARRAS, Jean Pierre. Administração de recursos humanos: do operacional ao estratégico. 3.ed. São Paulo: Futura, 2000.

MEGGinson, Leon C.; MOSLEY, Donald C.; PIETRI, Paul H., Administração: conceitos e aplicações. São Paulo: Harbra, c1986.

ROBBINS, Stephen P. Comportamento organizacional. 9. ed. São Paulo: Person Education: Prentice Hall, 2002.

RUIZ, João Álvaro. Metodologia Científica: Guia para eficiência nos resultados. 6. Ed. São Pailo: Atlas, 2006, p. 58.

SILVA, Renata Lange e SILUK, Julio Cezae Mairesse. Terceirização: O Outsourcing como ferramenta estratégica. Disponível em: https://www.google.com.br/search?q=TERCEIRIZA\%C3\%87\%C3\%830\%3A+O+OUTSOURCING+ COMO+FERRAMENTA+ESTRAT\%C3\% 89GICA\&ie=utf-8\&oe=utf-8\&client=firefox-bab\&gfe_rd=cr\&ei=BlFsV_iZFq7L8gfgkYbYBg> acesso em Junho de 2016. 
T. R. Mitchel, Motivation: new directions for theory and practices, Academy Management Review, 7ed., 1982, p. 80.

VERGARA, Sylvia Constant. Projetos e relatórios de pesquisa em administração. 10. ed. São Paulo: Atlas, 2009.

\section{Como citar este artigo (Formato ABNT):}

SANTANA, P.B.O.; ANDRADE, D.C.R.; JESUS, J.A.S. Terceirização na Administração Pública: Análise da Motivação dos Colaboradores Terceirizados no Serviço Público. Id on Line Revista Multidisciplinar e de Psicologia, Julho de 2016, vol.10, n.30, Supl 1, p. 68-84. ISSN 1981-1179.

Recebido: $14 / 06 / 2016$

Aceito: 27/06/2016 